\section{Rock e imaginário: as relações imagético-sonoras na atualidade}

\begin{abstract}
RESUMO
Este artigo descreve as intensas relações entre imagem e som na época contemporânea, com um enfoque no rock como 0 estilo musical característico da cultura pós-moderna. Também apresenta dois elementos importantes que envolvem a música: a técnica e a estética. A tecnologia implica uma mudança na forma que escutamos música e a estética liga os músicos aos seus fãs, em um processo de tribalização, conforme o conceito de Maffesoli. As principais características do rock (fluidez, mistura de estilos e gêneros, etc) também são enfatizadas a fim de apontar que ele pertence ao modo de vida pós-moderno. 0 rock é tanto um produto cultural quanto é produtor de uma cultura que pode ser desfrutada e interpretada pela sociedade contemporânea.
\end{abstract}

\begin{abstract}
The present paper describes the intense relations between imagery and sound in contemporary age, focusing on rock as the music style of post-modern culture. It also shows that music is wrapped up in two important elements: technology and aesthetics. Technology implies a change in the way we listen to music and aesthetics links up musicians and their fans into a tribalization process, as concived by the French author Maffesoli. The main cha-racteristics of rock n'roll (fluidity, mixing of styles and genres and so on) are also stressed, in order to point out that they belong to the post-modern way of life and that it is also a cultural product as much as it produces a culture that can be enjoyed and interpreted by contemporary society.
\end{abstract}

\section{PALAVRAS-CHAVE (KEY WORDS) \\ - Estética (Aesthetics) \\ - Som e Imagem (Sound and Image) \\ - Pós-modernidade (Postmodernity)}

\section{Adriana Amaral}

Mestre em Comunicação Social pela FAMECOS/PUCRS
NO MUNDO CONTEMPORÂNEO OU pós-modero, a "Imagem" é a musa sedutora. Tendese a desconsiderar os sons, os ruídos e a própria música como seus elementos. A imagem e os outros componentes do sentido da visão definem a marca de nossa época. Conforme descreve Maffesoli (1999):

A imagem vivida no cotidiano, a imagem banal das lembranças, a imagem dos rituais diários, imobiliza o tempo que passa. Seja a da publicidade, a da teatralidade urbana, a da televisão onipresente, ou a dos objetos a consumir, sempre insignificante ou frívola, ela não deixa de delimitar um ambiente que delimita bem a experiência estética da pósmodernidade.(Maffe-soli,1999, p.112)

Se para Maffesoli (1999) a imagem faz com que o conjunto social em seu todo seja mais resistente aos poderes estabelecidos, para Guy Debord (2000), esse reinado da aparência, definidor da contemporaneidade, apresenta-se como uma dimensão alienante do modus vivendi social. A essa condição de produção na vida societal ele chamou de sociedade do espetáculo. "Sob todas as suas formas particulares - informação ou propaganda, publicidade ou consumo direto de divertimentos - 0 espetáculo constitui o modelo atual da vida dominante na sociedade" (Debord, 2000, p.14).

A espetacularização da cultura, da economia, da arte, da vida humana como um todo tem no circuito da mídia sua principal vitrine. A partir de sua perspectiva acidamente crítica ao espetáculo como reconstrução de material e técnica da 
religiosidade, Debord (2000, p.18) afirma que "quando o mundo real se transforma em simples imagens, as simples imagens tornam-se seres reais e motivações eficientes de um comportamento hipnótico".

A tendência ao endeusamento e, por conseqüência, a uma fetichização da imagem faz com que nos concentremos apenas na veloz sucessão de frames que perpassam o controle remoto em um zapping contínuo do mundo. Assim, recortamos e colamos não só imagens propriamente ditas, como sons, ruídos e músicas, tramando uma verdadeira sinfonia visual do presente. Baudrillard (1997) chama atenção para a edição non-stop do real, em que

"vemos, de fato, a proliferação das redes, dos cabos, dos programas, com o desaparecimento e a liquidificação dos conteúdos. O zapping quase involuntário do telespectador fazendo eco ao zapping da TV sobre si mesma". (Baudrillard,1997, p.159)

As múltiplas relações entre música e imagem desenham-se nesse contexto de mudanças estéticas, sociais e culturais. A velocidade, a fragmentação, a cultura enquanto produto e a crescente informatização mudaram definitivamente o pensamento sobre a arte. Os samplers, estúdios, softwares de composição musical, enfim, todo o aparato digital à disposição dos sentidos e do bolso, facilitam a técnica e criam um novo paradigma na seleção auditiva e visual feita pelos sentidos. A ruptura entre o que se escutava antes e o que se ouve agora deu-se através das novas possibilidades técnicas relacionadas ao som.

Lévy (1993) define os elementos tecnológicos responsáveis pela transformação sonora: seqüenciador, sampler, sintetizador. $\mathrm{O}$ autor acredita que no surgimento dos instrumentos digitais está contida "uma ruptura comparável à da invenção da notação ou ao surgimento do disco". (Lévy, 1993, p.106) O sampler é capaz de gravar qualquer timbre e reproduzi-lo em todos os ritmos e alturas desejados. O resultado disso é que tanto o som característico de um instrumento como o de uma voz podem ser utilizadas para "tocar um trecho que o instrumentista ou cantor nunca tocou".(Lévy, 1993, p.104). Wisnik (1999) complementa esse conceito ao dizer que o sampler é um "tipo de teclado eletrônico que decompõe alturas melódicas em pulsos rítmicos" (Wisnik,1999, p.221). Para Lévy (1993), o seqüenciador funciona como um tipo de processador de texto musical. A manipulação e a gravação de uma série de códigos digitais que poderão controlar a execução de várias seqüências sonoras em sincronia em um ou mais sintetizadores são os recursos que o seqüenciador oferece ao músico. Quanto ao sintetizador, é um instrumento que controla totalmente o som, programando independentemente timbre, altura, intensidade e duração dos sons, afinal eles estão em códigos digitais e não dependem mais da vibração, como nos instrumentos analógicos.

As transformações na área de digitalização sonora influenciam diretamente a música produzida e afetam a música pop, passam pela produção de áudio publicitária, até os compositores contemporâneos. Os elementos técnicos da música evitam sua idealização como pura expressão estética e mostram o paradoxo entre emoção e tecnologia nela contido. Dualidades típicas do estágio cultural que ressoam nos ouvidos contemporâneos. O discurso da arte como todos os outros apresenta confusões e superposições, apresentando reestruturações no espaço e no tempo. Sfez (1999) comenta a qualidade abrangente dos paradoxos modernos que podem ser observados na arte e, nesse caso, na música (pois ela contém elementos tecnológicos e ao mesmo tempo suscita sentimentos e emoções).

O amálgama de sentimentos e de 
tecnologia que acontece na arte adquire importância, uma vez que o rock, enquanto fenômeno social da contemporaneidade, apresenta esses paradoxos desde a sua criação até o momento presente. Talvez a arte, e por sua vez a música, sempre tenha contido tais aspectos paradoxais em sua essência. Todavia, no jogo de ambigüidades da cultura contemporânea e em suas imbricações com a tecnologia, estes ressaltam aos sentidos, principalmente por sua exposição midiática.

De uma forma mais poética, os paradoxos da arte também aparecem na literatura do escritor indiano Salman Rushdie (1999), no romance O chão que ela pisa (uma transposição do mito de Orfeu, o deus grego da música, para a época atual). Quando o personagem Ormus Cama - líder de uma banda de rock - está gravando seu álbum, ele utiliza um estúdio cheio de parafernálias eletrônicas de toda ordem. O seu então produtor aconselha-o a simplesmente não se preocupar com o caráter da perda da emoção na criação da música em função da técnica, sentenciando que "as soluções dos problemas em arte são sempre técnicas. O sentido é técnico. O coração também". (Rushdie, 1999, p.303)

Os impactos das tecnologias de gravação, reprodução e distribuição, além, é claro, dos próprios instrumentos compõem uma melodia para a compreensão do papel da arte e dos artistas na cultura contemporânea, assim como na construção do imaginário dos fãs. Um exemplo emblemático desse impacto está na introdução da guitarra como elemento mítico da cultura pop.

Décadas antes do sampler, a guitarra elétrica causou grande furor na cultura jovem quando o folk/country branco e o blues negro, estilos originariamente acústicos nascidos nas entranhas dos Estados Unidos da América, foram eletrificados com a presença da guitarra. Dessa cópula maldita originou-se o que se chama de rock n' roll.
A estética constitui o outro elemento fundamental da arte e, geralmente, é o que propicia o estabelecimento da identificação entre os artistas e os fãs. Quando me refiro à estética, não estou tratando da idealização do belo. Trato de uma estética que se preocupa com as transformações do mundo contemporâneo. Uma estética decadente e também ascendente e afirmativa, cujos valores representem uma desconstrução dos valores anteriores, e que se vincule aos sentidos do corpo, ou seja, uma estética em que a emoção permaneça ligada ao próprio sentido da vida. A necessidade de incorporação das contradições inerentes à essência da arte e do artista faz dela uma estética fisiológica como enunciada por Nietzsche (1999).

De acordo com o autor, para que haja arte não é necessário que nos atenhamos aos conceitos de "verdadeiro" e de "nãoverdadeiro", mas "para que haja uma ação e visualização estéticas é incontornável uma precondição fisiológica: a embriaguez" (Nietzsche, 2000, p.70). A embriaguez é o sentimento de elevação da força e da plenitude que se encontram nos conceitos de apolíneo e de dionisíaco. A embriaguez apolínea está relacionada ao sentido da visão, do olhar, como o dos pintores e escultores, enquanto que na instância dionisíaca todos os sentidos apresentamse mais exaltados. Por isso, artes como a música e o teatro tendem a estar mais ligadas a ela.

A música, tal como a compreendemos hoje, é igualmente uma excitação e uma descarga conjunta dos afetos, mas não obstante, apenas o que sobrou de um mundo de expressão dos afetos muito mais pleno, um mero residuum do histrionismo dionisíaco (...) a música é a especificação lentamente alcançada deste estado, em detrimento das faculdades que lhe são mais intimamente aparentadas. (Nie-tzsche, 2000, p. 71) 
Partindo de uma concepção estética na qual a música constitui uma descarga de afetos, a produção contemporânea pode ser entendida como "uma polifonia de simultaneidades que está perto do ininteligível e insuportável" (Wisnik, 1999, p.53). A repetição e a alternância entre ruído e silêncio e as experiências de sincronia e simultaneidade tanto podem atestar o fim do social como podem criar um tempo musical singular para outros, de extrema complexidade e sutileza. O rock encontra-se no meio desse fogo cruzado, uma hibridação típica da cultura pósmoderna, conforme descreve Wisnik (1999, p.98):

O rock é a superfície de um tempo que se tornou polirrítmico. Progresso, regressão, retorno, migração, liquidação, vários mitos do tempo dançam simultaneamente no imaginário e no gestuário contemporâneos, numa sobreposição acelerada de fases e defasagens.

Em meio à abundância sígnica, esquecemos o valor comunicacional da música e de sua linguagem. Abandonamos em algum canto do lado esquerdo do cérebro as ligações entre o processo de escuta, o processo de construção sonora e as imagens, compartimentando o conhecimento e a sensorialidade. Para os sensíveis afortunados que não esquecem das relações entre os três elementos descritos acima, as possibilidades de experimentação ampliam-se, demonstrando que a utilização da tecnologia transforma os tormentos em arte e redimensiona o valor da linguagem musical.

Nesse sentido, as ligações cognitivas entre a música, a técnica e a linguagem aproximam-se à tríade cérebro-espíritocultura, da teoria da complexidade de Morin (1999, p.102). Ele destaca que nessa relação tríplice, a principal característica é a interdependência, na qual "cada instância contém, de certa maneira, as duas outras". Em sua proposta de reforma do pensamento, o autor defende que tanto as qualidades racionais e lógicas quanto as espirituais, artísticas e emocionais interligam-se a fim de que se obtenha um tipo de conhecimento no qual "o todo está na parte que está no todo, e a parte poderia estar mais ou menos apta a regenerar o todo" (Morin,1999, p. 126). O conhecimento não pode separar diferentes instâncias - no caso a escuta, a linguagem musical e as imagens.

Segundo Morin (1999, p.19), "para conhecer não podemos isolar uma palavra, uma informação; é necessário ligá-la a um contexto e mobilizar o nosso saber, a nossa cultura, para chegar a um conhecimento apropriado e oportuno da mesma". Os três processos acima descritos estão aglutinados em um circuito comunicacional e descrevem um mosaico sonoro-visual no qual a arte delineia um imaginário, apresentado pelos meios de comunicação de massa. A partir deles novas formas de socialidade são geradas, através das tribos de admiradores. Maffesoli (1999) afirma que o neotribalismo aponta para a estética como principal responsável pela construção de um laço afetivo entre os indivíduos, sendo um vetor fundamental das sociedades pós-modernas.

Segundo o autor, o neotribalismo não está mais inscrito no quadro de uma história moral e/ou política e muito menos situa-se contra a história, mas está à margem dela. Através de sentimentos e afinidades comuns há uma partilha de experiências em um estar-junto baseado no cotidiano, na futilidade e não mais nas grandes narrativas históricas. O vínculo social entre as tribos funciona a partir de uma lógica da identificação, na qual a cultura do sentimento é a conseqüência da atração.

Em sua descrição e análise das aparências nas sociedades contemporâneas, o autor aponta uma ética da estética no domínio da vida cotidiana, em que as uniões se constroem através de 
critérios subjetivos que desafiam a lógica e o racional, tão exaltados pela modernidade. A subjetividade e a sensibilidade são resgatadas dos momentos orgiásticos e dionisíacos pela pós-modernidade. O instrumental teórico- culturalista de Maffesoli (1999) possibilita uma bela audição do social em formação. No caso específico do rock, permite a observação da multiplicidade de sentidos e a reavaliação da incorporação de elementos como a "sujeira"1 e o "ruído"2, que, ao invés de desqualificarem o estilo, o tornam ainda mais interessante na construção de uma identidade cultural. A partir da sociologia compreensiva pode-se analisar o rock como um estilo que pode ser (re)-apropriado de várias formas por seus admiradores/ receptores, que interpretam e inferem sua mensagem ao seu bel-prazer.

Enquanto formadora de valores morais a serem consumidos na forma de imagens, a mídia agrega grupos com diferentes morais, éticas e objetivos, aquilo que Nietzsche $(1992, \S 199)$ prenuncia acerca do devir e conceitua como rebanhos humanos:

$\mathrm{Na}$ medida em que sempre, desde que existem homens, houve também rebanhos de homens (clãs, comunidades, tribos, povos, Estados, Igrejas) e sempre muitos que obedeceram, em relação ao pequeno número dos que mandaram.

Os rebanhos humanos da filosofia nietzschiana seguem uma espécie de consciência formal que lhes diz o que devem ser e o que devem ou não fazer. Essa visão aparentemente pessimista sobre os grupos sociais, ao mesmo tempo que parece estar inserida - na medida em que os meios de comunicação criam apelos diários e estímulos aos agrupamentos, lançando modas, artistas, objetos, todos passíveis de transformarem-se em totem de culto e de arrebatarem seguidores unidos pela admiração comum, vide o caso dos fãs -, contrasta com a noção de neotribalismo de Maffesoli, pois os grupos sociais formados através de vínculos de gosto o são por escolha própria e não por obediência a determinados moralismos.

Equilibrando-se na tênue linha entre o hedonismo e a generosidade coletiva, o estilo dos comportamentos juvenis possui "uma desenvoltura afetada em relação a certos valores estabelecidos e uma busca de autenticidade nos comportamentos" (Maffesoli, 1995, p.47). Na dinâmica paradoxal dessa cultura em formação, o sentimento de re-ligare ${ }^{3}$ do qual trata Maffesoli (1995) aparece com mais força. O re-ligamento vem à tona na superfície social, como algo fútil, banal, trivial, que remete a um certo romantismo que tem na arte uma inspiração constante, uma energia vital. Cabe aqui posicionar a arte num patamar de possível elemento dessa ligação entre as pessoas como descrito por Nietzsche (1992, §188): "E sempre surgiu alguma coisa pela qual vale a pena viver na terra, como virtude, arte, música, dança, razão, espiritualidade - alguma coisa transfiguradora, refinada, louca e divina".

Antes de pensar a música e os sons, convém lembrar do sentido que nos permite a conexão entre os elementos sonoros e o corpo humano: a escuta. Barthes (1990) dá conta de que o sentido da escuta está essencialmente ligado à avaliação da situação espaço-temporal e à demarcação do território, além de ser um exercício de seleção de signos. Nas sociedades em que a oralidade era de máxima importância para a transmissão de conhecimentos, o ritmo desponta como uma verdadeira marcação da linguagem. A reprodução intencional de um ritmo vem antes da invenção da escrita. "Sem ritmo nenhuma linguagem seria possível: o signo baseia-se num ir e vir do marcado e do não-marcado que chamamos de paradigma"(Barthes, 1990, p.220).

Para além da escuta e da oralidade, o poder da linguagem musical do qual nos fala Wisnik (1999) aponta para o caráter virtual do som e de como ele povoa nosso imaginário através do impalpável e do invisível, opondo-se assim à materialidade do tato e da visão, identificados pelo senso 
comum como os sentidos mais próximos da realidade.

Percebe-se na música importantes características estéticas daquilo que Maffesoli (1995) observa como um fator de união e/ou desagregação de grupos/ tribos em potenciais e que para Nietzsche (1992) é a energia criativa do mundo. Para Wisnik (1999), a música é um elemento coordenador das sociedades, funcionando como mito fundador sacrificial das mais variadas culturas, pois de acordo com sua antropologia do ruído:

Um único som afinado, cantado em uníssono por um grupo humano, tem o poder mágico de evocar uma fundação cósmica: insemina-se coletivamente, no meio dos ruídos do mundo, um princípio ordenador. (...) As sociedades existem na medida em que possam fazer música. (Wisnik,1999, p.33-34)

A socialização que a música traz aos grupos sociais remete ao gênio coletivo como formador do valor estético:

Assim, aquela estrela esportiva ou cantor de rock, aquele homem de negócios ou apresentador de televisão, aquele guru intelectual ou religioso, e até mesmo aquele animal em evidência no turfe semanal vai, por algum tempo, cristalizar o gênio coletivo. Por intermédio dessa cristalização, vão-se constituir microcomunidades.(Maffe soli, 1995, p.39)

O fator de socialização que a música apresenta possibilitou a constituição do rock n'roll como uma forma de manifestação cultural que transcende limites sociais, culturais e geográficos, ganhando a mente dos jovens a partir da década de 50 , pipocando sua sonoridade nos mais variados cruzamentos do mundo. O caráter paradoxal, ambíguo e mundializado do rock o torna a música da contemporaneidade, fazendo-o facilmente passível de identificação, bem como servindo de totem de adoração a determinados grupos de indivíduos, conforme explicita Connor (1997):

Rock music embodies to perfection the central paradox of contemporary mass culture, in the fact of its unifying global reach and influence on the one hand combined with its tolerance and engendering of pluralities of styles, media and ethnic identities on the other.(Connor, 1997, p.207)

Além de global, é da natureza do rock'n'roll agrupar características locais através de uma fluidez. A partir dos conturbados anos 60 , o rock implica uma cultura jovem que "se tornou a matriz da revolução cultural no sentido mais amplo de uma revolução nos modos e costumes, nos meios de gozar o lazer e nas artes comerciais, que formavam cada vez mais a atmosfera respirada por homens e mulheres urbanos." (Hobsbawn,1995, p.323)

O rock faz parte da cultura de consumo e apresenta-se como produto globalizado de assimilação universal, assim como o blue jeans e a coca-cola, incorporando paralelamente trejeitos locais sonora e esteticamente. Para Chesneaux (1996), esses modelos de consumo e comportamento impõemse massificadamente em todas as extremidades do planeta nas vidas cotidianas de cada um. E é através da mídia que essas culturas se estendem por todas as regiões da Terra, interferindo no conteúdo de diferentes universos mentais, construindo, conforme Chesneaux (1996,p.53), "um imaginário coletivo, compósito e fictício" percebido no mundo globalizado.

A globalização/mundialização ${ }^{4}$, cuja gênese remonta ao iluminismo e ao liberalismo, é caracterizada pela fluidez das trocas e intercâmbios de mercadorias e idéias, resultando no movimento de integração mundial que teve início na virada do século XIX. Mattelart (2000, 
p.11) associa o fenômeno da globalização aos meios de comunicação, principalmente em seu papel de construtor de valores e de conexão das sociedades e culturas.

Os instrumentos de comunicação permitem que um produto cultural como o rock esteja presente em cidades tão distintas quanto Los Angeles, Dublin ou Porto Alegre.

Os mesmos impulsos de subjetividade ambígua levam centenas de milhares, se não milhões de pessoas a se identificar com as excentricidades da cantora Madonna, com as decepções que os testes antidoping infligem às estrelas olímpicas, com as engenhosas contorções publicitárias, vendendo os direitos da Coca-Cola, com as dificuldades da nave Discovery, com as proezas do jogador Maradona, com as percussões brutais dos Rolling Stones.(Chesneaux, 1996, p.54).

Nesses tempos de radicalização e difusão das estruturas culturais, há uma diferente percepção do espaço e do tempo. Harvey (1992) afirma que a aceleração é uma constante, inclusive no âmbito cultural. O "tempo de vida" de uma ida ao museu, a um concerto de rock ou o sucesso de determinado ator, embora difícil de estimar, tende a ser menor do que o de um carro ou de uma máquina de lavar roupas. A compressão espaço-temporal acentua a "volatilidade e a efemeridade das modas, produtos, técnicas de produção, processos de trabalho, idéias e ideologias, valores e práticas estabelecidas." (Harvey, 1992, p.258)

Outro fator é a ênfase dada a valores e virtudes como a instantaneidade e a descartabilidade em uma troca de estilos por temporada, exatamente como nos desfiles de moda, em que as tendências são substituídas e/ou transformadas a cada estação.

Um eterno vestir e despir de identidades. Os estilos dentro do próprio rock - hippie, punk, heavy metal, new wave, gótico, britpop, etc. segmentam-se, alternam-se e/ou sucedemse em uma constante negação/aceitação e transmutação em uma inter/intra-relação com os mais variados tipos de música, moda e arte, garantindo dessa maneira sua permanência na indústria cultural.

É o estilo estético que Maffesoli (1995) vislumbra como a caracterização, o definidor de uma determinada época. Essa conjunção cósmica do sentir em comum, segundo o autor, está muito próxima do espírito romântico e pode ser facilmente observada nos ídolos do rock. Hobsbawm (1995) explicita que a figura do ídolo rebelde é essencialmente romântica e traz à tona, através da mídia, o mito do "herói cuja vida e juventude acabavam juntas. Essa figura, antecipada na década de 50 pelo astro de cinema James Dean, foi comum, talvez mesmo um ideal típico, no que se tornou a expressão cultural característica da juventude - o rock". (Hobsbawm, 1995, p.318)

A rebeldia e a insatisfação com o mundo e com os padrões estabelecidos os quais o rock tenta transgredir, já estão incorporadas à própria indústria cultural. A mercantilização e a transformação da arte em produto de massa são inevitáveis. Para Connor (1997), desde suas raízes, o rock, como nenhum outro estilo musical, incorpora as ambigüidades e os paradoxos da pós-modernidade. Ele possui um caráter dualista, ao mesmo tempo apocalíptico e integrado, misturando rebeldia e submissão, arte e tecnologia, modernidade e pós-modernidade.

O rock como forma de manifestação cultural iniciou no pós-guerra (década de 50), mas atingiu um público maior depois, via programas de rádio, de TV, filmes e de outros produtos culturais. Assim, a cultura rock espalha suas sementes com um sopro de vento durante a atmosfera cultural efervescente da década de 60. Milhares de jovens, portando uma guitarra, decidiram montar sua própria banda. O período também é marcado pela disseminação da cultura jovem norte-americana, inclusive na própria Europa, outrora o berço das novas tendências e comportamentos. 
Já a década de 70 inaugura o tempo de consumo enquanto novo mito social, transformando-se em critério de avaliação do grau de "sucesso" e felicidade das pessoas e dos grupos. O homem não está mais rodeado por outros homens, e sim por objetos que demarcam o seu status social. A celebração dos bens materiais nos massmedia é classificatória, pois atende a uma lógica da produção e da manipulação dos significantes sociais e relega as relações sociais humanas a um segundo plano. Além disso, refere-se ao consumo como equivalente à felicidade.

Featherstone (1994) apresenta um levantamento das principais teorias da cultura de consumo, evidenciando as implicações do inter-relacionamento entre cultura, economia e sociedade. O autor identifica três perspectivas fundamentais para compreendermos o processo de transformação do consumo em cultura. A primeira delas é constituída pelos sonhos, os prazeres emocionais e os desejos celebrados no imaginário cultural. A expansão da produção capitalista de mercadorias, que deu origem a uma vasta acumulação de bens e locais de compra, e a utilização das mercadorias como forma de estabelecer distinções ou de criar vínculos são as outras duas perspectivas.

Baudrillard (1995) classifica esta época como o tempo dos objetos. O estabelecimento do consumo como principal característica da sociedade do século XX se dá principalmente pelas mãos da publicidade e propaganda. Dessa forma, compramos apenas signos que nos garantem a segurança, sendo assim, negamos a realidade pelo seu conforto, recusando o real em favor do simulacro. Paralelo ao consumo, o estudo da cultura de massa pelos intelectuais floresceu substancialmente na década de 80 , em muitos casos optando-se por posições menos elitistas do que as das décadas anteriores, que só viam os pontos negativos da cultura de massa.

Rotulada anteriormente como prática cultural de classes subalternas, a cultura de massa ganhou status nos 80 devido às mudanças na indústria cultural $e$, principalmente, aos grandes investimentos de capital nos estúdios de Hollywood e nas séries de televisão. As relações entre classes sociais e as formas de bens culturais já não mostram a enorme variedade de culturas produzidas pelas mais diversas classes.

Além do fator tecnológico que propiciou a popularização da música e do vídeo, entre outros, também o pós-modernismo possibilitou a reavaliação da cultura de massa, colocando-a em novos patamares, por artistas, escritores, críticos, arquitetos, etc. Com esses primeiros passos em direção à aceitação da cultura pop, os esportes, os seriados de televisão, a literatura de massa e o rock n'roll, entre outras formas de arte popular, tornam-se parte de estudos culturais mais aprofundados e detalhados nas universidades. E, embora ainda existam preconceitos, as questões levantadas nesses estudos continuam contribuindo para novas leituras e avaliações dos fenômenos culturais contemporâneos.

Ao contrário das décadas anteriores, os anos 80 não criaram movimentos culturais juvenis, como acontecera antes com os hippies, os punks e a própria disco. A regra foi a de ser um pouco de tudo. Pular de tribo em tribo em um ecletismo jamais imaginado anteriormente. A releitura dos estilos caracterizou o período. O fenômeno dos revivals ${ }^{5}$ tem início justamente quando as infinitas releituras e citações de tendências, musicais ou comportamentais de anos anteriores, aparecem em diversas localidades. A arte transforma-se em uma confluência de estilos.

Após esse curto retrospecto observase que o imaginário do rock é produto direto de um período de rupturas na sociedade e na cultura, no qual a mídia serve como espelho, refletindo e sendo refletida pela sociedade contemporânea. As relação intrínsecas entre música e imagem 
que se constroem em torno dela são elementos que denotam a transformação dos paradigmas da modernidade. Sobre essas mudanças, Wisnik (1999) comenta que o barulho e os ruídos - muitas vezes atribuídos ao rock pelos "mais velhos" - têm uma grande importância, pois passam a ser concebidos como elementos integrantes da música, afetando assim a escuta e alterando os padrões estéticos. Dentro desse contexto, o jazz, as músicas populares, o minimalismo e, principalmente, o rock apontam para um deslocamento dos parâmetros sonoros, orquestrando uma nova forma de ouvir e de sentir a música:

Entre os impasses declarados de algumas das linhas evolutivas da modernidade e o impacto da repetição nos meios e massa, fica impossível pensar a multiplicidade das músicas contemporâneas a não ser através de novos parâmetros.(Wisnik, 1999, p.11).

Esses novos parâmetros incorporam o rock e a música pop enquanto elementos culturais definidores de um tempo no qual a música encontra-se além da técnica e da estética e no qual a mídia e as tecnologias tanto formam os valores estéticos como servem de vetores entre a imagem de determinados artistas e os grupos de fãs - tribos - que gravitam em torno deles.

\section{Notas}

10 rock muitas vezes incorpora um caráter de glamour à sujeira, vide os exemplos do Punk nas décadas de 70/80 (em inglês original, vagabundo) e do Grunge nos anos 90, dois movimentos dentro do rock no qual o "parecer sujo" fazia parte estética e filosoficamente, refletindo nas roupas e no visual tanto quanto na sonoridade de guitarras distorcidas, vocais berrados e, em geral, desafinados.

2 "O ruído cerca o som como uma aura. 0 som desponta alegre e dolorosamente em meio ao ruído. 0 social se inscreve sacrificialmente (como uma tatuagem sonora) no corpo, e essa inscrição ruidosa, que nega o ruído, funda e mantém o som." (Wisnik, 1999, p.40)

3 Para 0 autor, dentro dessa lógica de identificação de estilos, a imagem torna-se um vetor de comunhão, sendo "religante", isto é, "ela une ao mundo que cerca, ela une aos outros que me rodeiam". (Maffesoli, 1995, p.18)

4 Mattelart (2000, p.11) faz uma diferenciação entre os dois termos a partir de sua origem: "O primeiro termo é familiar a todas as línguas neolatinas, o segundo é de origem anglo-saxônica". Para 0 autor, a mundialização estaria mais ligada à cultura enquanto que a globalização referese à economia.

5 Revival: Do inglês, reviver. 0 revival é a experiência de resgatar determinada época ou período histórico através de sua moda e dos estilos.

\section{Referências}

BARTHES, Roland. 0 óbvio e o obtuso. Rio de Janeiro: Nova Fronteira, 1990.

BAUDRILLARD, Jean. A sociedade de consumo. Lisboa: Edições 70, 1995.

BAUDRILLARD, Jean. Tela Total. Mito-ironias da era do virtual e da imagem. Porto Alegre: Sulina, 1997.

CHESNEAUX, Jean. Modernidade-mundo. São Paulo: Vozes, 1995.

CONNOR, Steven. Postmodernist culture. Introduction to theories of the contemporary. Oxford: Blackwell Publishers, 1997.

DEBORD, Guy. A sociedade do espetáculo. Rio de Janeiro: Contraponto, 2000.

FEATHERSTONE, Mike. Cultura de consumo e pósmodernismo. São Paulo: Studio Nobel, 1994.

FINKIELKRAUT, Alain. A derrota do pensamento. Rio de Janeiro: Paz e Terra, 1989.

HOBSBAWM, Eric J. A era dos extremos. O breve século XX 1914-1991. São Paulo: Cia. Das Letras, 1995. 
HARVEY, David. A condição pós-moderna. São Paulo: Loyola, 1992. 349p.

LÉVY, Pierre. As tecnologias da inteligência. São Paulo: Editora 34, 1993.

MAFFESOLI, Michel. A contemplação do mundo. Porto Alegre: Artes e Ofícios, 1995.

MAFFESOLI, Michel. No fundo das aparências. Rio de Janeiro: Vozes, $2^{\mathrm{a}}$ ed., 1999.

MARTINS, Francisco M. e SILVA, Juremir M. (orgs.). Para navegar no século 21 - tecnologias do imaginário e cibercultura. Porto Alegre: Sulina / Edipucrs, 1999.

MATTELART, Armand. A globalização da comunicação. São Paulo: EDUSC, 2000.

MORIN, Edgar. O Método. Volume 3 - o conhecimento do conhecimento. Porto Alegre: Sulina, 1999.

NIETZSCHE, Friedrich. Além do bem e do mal. Prelúdio a uma filosofia do futuro. São Paulo: Cia. das Letras, 1992.

NIETZSCHE, Friedrich. 0 caso Wagner: um problema para músicos / Nietzsche contra Wagner: dossiê de um psicólogo. São Paulo: Cia. das Letras, 1999.

NIETZSCHE, Friedrich. Crepúsculo dos ídolos (ou como filosofar com o martelo). Rio de Janeiro: Relume Dumará, 2000.

RUSHDIE, Salman. 0 chão que ela pisa. São Paulo: Cia das Letras, 1999.

SFEZ, Lucien. As tecnologias do espírito. In: MARTINS, Francisco M. e SILVA, Juremir M. (orgs.). Para navegar no século 21 - tecnologias do imaginário e cibercultura. Porto Alegre: Sulina/Edipucrs, 1999.

WISNIK, José Miguel. O som e o sentido. Uma outra história das músicas. São Paulo: Companhia das Letras, $2^{2}$ ed.,1999. 